\title{
Depletion and Distribution Studies for Oxytetracycline in Broiler Chicken using Commercial ELISA with Subsequent Confirmatory Analysis by HPLC-UV
}

\author{
Mehwish Mumtaz*, Uzma Maqbool, Muhammad Ismail Chughtai, M. Salahuddin Shah and Ghulam Hussain \\ Animal Sciences Division, Nuclear Institute for Agriculture and Biology (NIAB), P.O. Box 128, Faisalabad-38000, Pakistan \\ *For correspondence: mehwish@niab.org.pk; mehwish.pieas@ hotmail.com \\ Received 07 September 2021; Accepted 22 November 2021; Published 15 December 2021
}

\begin{abstract}
Tetracyclines are commonly used in livestock for the treatment of various diseases. Their residues above the maximum residual limit-MRL (200 $\left.\mathrm{g} \mathrm{kg}^{-1}\right)$ can cause health hazard issues not only in humans but also in animals. For this purpose, efforts were made to study distribution and depletion profile of Oxytetracycline in broiler chicken by ELISA and HPLC. Regarding this, an experiment was conducted on healthy chickens of average weight $600 \pm 20 \mathrm{~g}$. Six broiler chickens were treated with formulation (OXTRA L.A.) containing Oxytetracycline dehydrate @ 20 ppk solution (150 $\mu \mathrm{L})$ equivalents to recommended dose $20 \mathrm{mg}$ kg${ }^{1}$ through intramuscular route, while control birds were untreated. Treated chickens were slaughtered at an interval of 1, 8, 16, 32, 64 and 120 h. Different tissue samples including liver, kidney, thigh and chest muscles were collected and screened by ELISA (Cat No. 5091TC, Euro Proxima). Lowest detection limit $\left(\mathrm{IC}_{20}\right)$ was calculated as $0.12 \mathrm{ng} \mathrm{mL}^{-1}$ and middle of the test $\left(\mathrm{IC}_{50}\right) 0.5 \mathrm{ng} \mathrm{mL}-1$ with recovery 75 to $86 \%$. Reverse phase liquid chromatography (HPLC-UV) method was also standardized by using range of standards from 25 to $200 \mu \mathrm{g} \mathrm{kg}^{-1}$. Calibration curve showed good response with correlation coefficient $\left(\mathrm{R}^{2}\right)$ 0.9727 and recovery 85 to $93 \%$. Overall, withdrawal period (<MRL) in all tissue samples was calculated as $117 \mathrm{~h}(4.8 \mathrm{days})$ by ELISA while $128 \mathrm{~h}$ (5 days) by HPLC-UV. Both validated methods can be further utilized to generate reliable data for food safety measures in Pakistan to enhance international trade. (C) 2021 Friends Science Publishers
\end{abstract}

Keywords: Oxytetracycline residues; Withdrawal period; Validation studies; ELISA; Liquid chromatography

Abbreviation: HPLC-UV: High Pressure Liquid Chromatography, Ultra Violet, ELISA: Enzyme-Linked Immunosorbent Assay, WHO: World Health Organization, MRM: Maximum Residue Limit, FDA: Food and Drug Administration, CODEX: Alimentarius Collection of Food Standards, JECFA: Joint FAO/WHO Expert Committee on Food Additives

\section{Introduction}

Food safety is of great importance these days, especially in a world where monitoring studies is favorable in search of safe food. Local people are unaware of ill practices used in antibiotics in livestock sector, several efforts are being made to reduce antibiotics use (Rana et al. 2019). This is due to non-existence of strict regulations and lack of food safety awareness to public. Antibiotics are most commonly used in poultry but hardly examined (Khatun et al. 2018). Their illegal use can increase the chances of food contamination instead of their benefits, e.g., creates resistance in human pathogens (Al-Gendy et al. 2014).

Antibiotics are widely used in animals to control diseases as well as growth promoter to increase meat, milk and egg production (Wang et al. 2011). The tetracyclines have applications for the treatment of infections in poultry, cattle, sheep, and swine. In some cases, for therapeutic treatment of large numbers of poultry reared on commercial farms, the antibiotics are added directly to feed or water or can be administered (Khatun et al. 2018). The presence of drug residues in animal-derived food can cause serious health issues. Due to this reason, food safety has become a serious concern all over the world (Biswas et al. 2007). The inappropriate and overuse of veterinary drugs has become a common practice in recent years (CODEX 2012).

The main group of drugs used in veterinary medicine include tetracyclines, amphenicols, aminoglycosides, macrolides, nitrofurans, nitromidazoles, sulfonamides and quinolones (Ang et al. 2017).

Tetracyclines are effective against Gram-positive and Gram-negative bacteria, including some anaerobes. Susceptible organisms include Escherichia coli, Klebsiella species, Pasteurella species, Salmonella species, and Streptococcus species. Tetracyclines are also active against chlamydia, mycoplasmas, some protozoan and several

To cite this paper: Mumtaz M, U Maqbool, MI Chughtai, MS Shah, G Hussain (2021). Depletion and distribution studies for oxytetracycline in broiler chicken using commercial ELISA with subsequent confirmatory analysis by HPLC-UV. Intl J Agric Biol 26:741-749 
rickettsia. Drugs are mostly used in broiler chickens to treat chronic respiratory disease and infectious sinusitis, it is also suitable to enhance immune system in farm produce animals (Shahid et al. 2007; Wang et al. 2011).

Tetracyclines inhibit protein synthesis in both bacterial and human cells, the first members which were derived from the Streptomyces genus of Actinobacteria. Oxytetracycline and chlortetracycline show moderate lipid solubilities while doxycycline and minocycline show higher, so that they are able to traverse cell membranes moderately or readily (Wang et al. 2011). Tetracyclines after absorption bound to plasma protein to a limited extend, absorption percentage of tetracycline's in animal body is chlortetracycline 46-51\%, tetracycline $28-41 \%$, oxytetracycline $21-76 \%$ and doxycycline 84-92\% (Riviere and Papich 2018).

Chlortetracycline and oxytetracycline both discovered in the late 1940s, were the first members of the tetracycline group to be described, are commonly used in livestock sector to control diseases. If their depletion profile studies are not conducted then their residues will remains in edible tissues (Widiastuti and Anastasia 2015). Overuse of these drugs can cause microbial resistance. Hence, non-susceptible organisms grow rapidly; this may result in colitis and severe diarrhea (Wang et al. 2011). About 20 to $90 \%$ of the drugs are not adsorbed and excreted (EU Regulation 2010; Muaz et al. 2018).

Local farmers are unaware of actual withdrawal period of the antibiotics so the residues persist in the meat beyond safe limit (Mund et al. 2017; Xu et al. 2019). The continual use of the antibiotics in poultry also increases resistance against antibiotics not only in animals but also in consumers (Khatun et al. 2018; Muaz et al. 2018). This leads to rapid change in genetic variation of certain beneficial bacteria which become dangerous for the human life and their presence continued in environment (Agha et al. 2003).

The World Health Organization (WHO) reported public health problems emerging from microbial resistance due to excessive use of antibiotics (Cinquina et al. 2003). The Food and Drug Administration (FDA) also set criteria for the approval of new antibiotics to perform risk assessment (Biswas et al. 2007; Khatun et al. 2018). Codex and FAO/WHO experts set maximum residue levels for tetracyclines are $0.2,0.6$ and $1.2 \mu \mathrm{g} \mathrm{g}^{-1}$ for poultry muscle, liver and kidney; respectively. In order to ensure the customers food safety, plans for monitoring of contaminants in food are set by Codex (Al-Gendy et al. 2014; CODEX 2018). Similarly, tetracyclines MRL is described as the combination of parent compounds and its metabolites in poultry products, set as $200 \mathrm{ng} \mathrm{g}^{-1}$ for meat, $600 \mathrm{ng} \mathrm{g}^{-1}$ for liver and $400 \mathrm{ng} \mathrm{g}^{-1}$ for eggs. A group ADI for tetracycline, oxytetracycline, and chlortetracycline has been allocated by JECFA. The MRL value is also set by CAC for tetracycline, oxytetracycline and chlortetracycline applicable to cattle, sheep, pigs, poultry and fish while for giant prawn only oxytetracycline (Wang et al. 2011).

According to EU MRL limits for tetracyclines is set as
$100 \mu \mathrm{g} \mathrm{kg}^{-1}$ for muscles, $300 \mu \mathrm{g} \mathrm{kg}^{-1}$ for liver and $600 \mu \mathrm{g} \mathrm{kg}^{-1}$ for kidney (Commission Decision 2002; CODEX 2012). A strict surveillance system exists in the European Union by Council Directive 96/23/EC for screening of veterinary drug residue. Rapid alerts due to residues of antibiotics in broiler chicken and its products have been appeared in the market of Bangladesh, Indonesia, Oman and Philippines as their consignments are rejected by EU member states. Indonesia has also sets the MRL for oxytetracycline as $100 \mathrm{ng} \mathrm{g}^{-1}$ for meat and $50 \mathrm{ng} \mathrm{g}^{-1}$ for eggs through SNI No. 01-6366 2000 (Widiastuti and Anastasia 2015).

In Pakistan, oxytetracycline residues monitoring in Rawalpindi, Islamabad and Faisalabad regions was reported as $44.8 \%$ broiler chicken samples found positive as per recommendations of Joint FAO/WHO Committee of food additives (Shahid et al. 2007). Punjab Food Authority of Pakistan has also established a document for setting MRPL and MRL to control antibiotics by regular monitoring through different ministries. Screening of antibiotics through like commercial and in-house ELISA and subsequent confirmatory analysis of positive or selected samples by HPLC-UV is cost-effective to screen large number of samples (Cinquina et al. 2003). The present studies depict the procedure to determine withdrawal period of oxytetracycline in broiler chicken and drug distribution in different body parts of broiler chicken. The generated data can be applied to set withdrawal period of oxytetracycline. It can further contribute in giving awareness to the farmers and other stakeholders involved in this business as well as consumption.

\section{Materials and Methods}

\section{Chemicals and reagents used}

Trichloroacetic acid (Merck), Methanol (VWR), Oxalic acid (Sigma), nylon membrane PTFE membrane $(0.45 \mu \mathrm{m})$, syringe filter $(4 \mathrm{~mm})$, PP housing, double distilled water, (from Cyclon Firsteem Automatic Ultrapure Water Still) Filtration Assembly, Sartorius, Ethyl acetate (VWR), nHexane (VWR), Polycons (50 mL capacity, VWR), Glass test tubes (Kimax), Separatory funnels, Erlenmeyer flask, Commercial ELISA Kits (Cat. \# 5091TC, Europroxima, Netherlands), DMSO (Sigma), Trifloroacetic acid (Sigma) and Acetonitrile (VWR).

\section{Experimental planning and execution}

Experiments were conducted to determine drug profile in vitro. Regarding this, all requirements were fulfilled as mentioned in ARRIVE guidelines with the recommendations of NIAB animal house committee. Special considerations were taken to minimize the stressful conditions of the animals. A group of seven broiler chicken was grown under controlled conditions in NIAB Animal Farm House. Injectable Oxytetracycline products are stable as shown by the retention 
of more than $90 \%$ potency for at least 24 month storage (Ang et al. 2017). In group-I $(\mathrm{n}=6)$, which served as the treated or positive control, each bird received antibiotic-free water and feed until the end of the experiment. In the fifth week of the chickens' lives, a veterinary drug containing oxytetracycline dihydrate (OXTRA L.A. E.U.P $21.978 \mathrm{~g}$ equivalent to oxytetracycline $20 \mathrm{~g}$-excipients q.s. $100 \mathrm{~mL}$ (Bologna, Italy) was administered @ $0.15 \mathrm{~mL}$ per kg body weight. One bird was taken as negative control that was non-treated. Drug was administered to each broiler chicken at right thigh and breast side through intramuscular route. Five treated chickens were slaughtered after $1,8,16,32,64 \mathrm{~h}$ while $6^{\text {th }}$ after one week along with control. Selected tissue samples were collected and transferred to Food Safety Labs (ISO/IEC 17027:2017 accredited) of NIAB Faisalabad and stored at $-20^{\circ} \mathrm{C}$ till further analysis.

\section{Collection of samples}

For distribution and depletion profile studies of Oxytetracycline, different tissue organs (liver, kidney, thigh and chest) were selected. From these selected organs, total 42 treated including 6 control samples were collected for analysis. Detail of samples is given in Table 1:

\section{Preparation of standards and buffers}

Stock and working standards: Lyophilized stock standard $\left(2 \mu \mathrm{g} \mathrm{kg}^{-1}\right)$ was provided with ELISA kit. Tetracycline working dilutions were prepared including $0,0.025,0.125$, $0.25,0.5,1.0$ and $2.0 \mu \mathrm{g} \mathrm{kg}^{-1}$ with dilution buffer and stored at $-20^{\circ} \mathrm{C}$. A standard of $1000 \mu \mathrm{g} \mathrm{kg}^{-1}$ was also provided for spiking of negative control samples.

Dilution buffer: Prepared from $4 \mathrm{X}$ concentrate buffer by adding three times double distilled water.

Rinsing buffer: Prepared from 20X concentrate by dilution of $2 \mathrm{~mL}$ of buffer with $38 \mathrm{~mL}$ of double distilled water.

Sample dilution buffer: Prepared by adding $2 \mathrm{~mL} \mathrm{100 \%}$ methanol in $18 \mathrm{~mL}$ dilution buffer (mix and store at $4^{\circ} \mathrm{C}$ ).

Enzyme-linked conjugate: Concentrate centrifuged at 1000 rcf for $1 \mathrm{~min}$ before use, diluted with dilution buffer in proportion $(10 \mu \mathrm{L}: 1 \mathrm{~mL})$ and kept in dark until use.

\section{Preparation of tissue samples}

A sample weighing $1 \mathrm{~g}+0.01 \mathrm{~g}$ was taken in $50 \mathrm{~mL}$ polycon tube by using analytical balance (ATX224, Schmadzu). Added $0.5 \mathrm{~mL}$ double distilled water and $1.5 \mathrm{~mL}$ of $100 \%$ methanol. After mixing for $15 \mathrm{~min}$, samples were homogenized using tissue homogenizer (HG-15D, DAIHAN Scientific). Centrifuged (5430R, Eppendorf) for $5 \mathrm{~min}$ at $2000 \mathrm{rcf}$ at room temperature. Supernatant $50 \mu \mathrm{L}$ was transferred in glass tubes and mixed with $350 \mu \mathrm{L}$ of sample dilution buffer. After vortex for $1 \mathrm{~min}, 50 \mu \mathrm{L}$ of diluted samples was further used for assay development.

\section{Assay development}

As per layout plan (Table 2), ELISA was performed in the polystyrene 96 well microtiter plates (provided along the kit). For assay preparation, $50 \mu \mathrm{L}$ of each standard and/or samples and enzyme conjugate were added. After rocking and mixing, sealed the microtiter plate and incubate for $1 \mathrm{~h}$ at $20-25^{\circ} \mathrm{C}$. After incubation, microtiter plates were washed three times with washing buffer using Microplate ELISA Washer (BioTek, ELx50). After washing, added $100 \mu \mathrm{L}$ of substrate solution in all wells and incubate for $30 \mathrm{~min}$ at $20-25^{\circ} \mathrm{C}$ in dark to develop colour. After incubation, added $100 \mu \mathrm{L}$ stop solution (provided along kit) in each well, mixed gently by rocking the plate manually on top of the working bench and optical density was measured at $450 \mathrm{~nm}$ using Microplate ELISA Reader (BioTek. ELx808).

\section{Calculations}

The relative absorbance (RA) was calculated for both standards and samples by using the formula given below and Microsoft Excel was used to construct standards curve point by point. The RA of unknown samples was interpolated in standards curve to calculate the concentration of unknown samples.

$$
\text { Relative absorbance }(\%)=\frac{\text { Absorbance of standards (or samples) }}{\text { Absorbance of zero standard }} \times 100
$$

\section{Confirmatory analysis}

An HPLC system (HITACHI L-2000 series) equipped with UV-Vis detector (L-2420), column oven (L-2300) and autosampler (L-2200) was used for standardization and validation of oxytetracycline detection in tissue for analysis of selected positive tissue samples.

\section{HPLC conditions}

Agilent Zorbax Rx C8 Column (5 $\mu \mathrm{m}, 4.6 \mathrm{~mm}$ and $150 \mathrm{~mm})$ was used with mobile phase $0.1 \%$ TFA: ACN (75:25 v/v and filtered by filtration assembly using filter AG $0.45 \mu \mathrm{m}$, Sartorius) at $252 \mathrm{~nm}$ wavelength and $1.0 \mathrm{~mL}$ per min flow rate. Column oven temperature was set at $26^{\circ} \mathrm{C}$.

\section{Extraction and cleanup of samples}

Sample weighing $5 \mathrm{~g}+0.05 \mathrm{~g}$ muscle/tissue was transferred in $50 \mathrm{~mL}$ centrifuge tube and homogenized by for $30 \mathrm{~s}$ at $1000 \mathrm{rpm}$. Added $20 \mathrm{~mL}$ of $5 \%$ Trichloroacetic acid (TCA, Sigma), mixed it at $120 \mathrm{rpm}$ for $20 \mathrm{~min}$ in shaker (Julabo, $\mathrm{SW}(22)$, Germany) and centrifuged at conditions $4000 \mathrm{rpm}$, $25^{\circ} \mathrm{C}, 10 \mathrm{~min}$. Took the supernatant without disturbing the tissue and filtered it using cellulose filter paper, repeated extraction in twice using $10 \mathrm{~mL}$ of $5 \%$ TCA. Supernatant from 3 extractions were collected and filtered through 
Table 1: Details of Oxytetracycline treated selected tissue samples

\begin{tabular}{llll}
\hline Sampling matrix & No. of samples & Identification code & Sample quantity \\
\hline Left Thigh Muscle & 07 & $\mathrm{CHK}_{\mathrm{LT}}-18-001$ to $\mathrm{CHK}_{\mathrm{LT}}-18-007$ & $50 \mathrm{~g}$ \\
Kidney & 07 & $\mathrm{CHK}_{\mathrm{K}}-18-001$ to $\mathrm{CHK}_{\mathrm{K}}-18-007$ & $50 \mathrm{~g}$ \\
Liver & 07 & $\mathrm{CHK}_{\mathrm{L}}-18-001$ to $\mathrm{CHK}_{\mathrm{L}}-18-007$ & $20 \mathrm{~g}$ \\
Right Thigh Muscle & 07 & $\mathrm{CHK}_{\mathrm{R}-}-18-001$ to $\mathrm{CHK}_{\mathrm{RT}}-18-007$ & $50 \mathrm{~g}$ \\
Right Breast Muscle & 07 & $\mathrm{CHK}_{\mathrm{RB}}-18-001$ to $\mathrm{CHK}_{\mathrm{RB}}-18-007$ & $50 \mathrm{~g}$ \\
Left Breast Muscle & 07 & $\mathrm{CHK}_{\mathrm{LB}}-18-001$ to $\mathrm{CHK}_{\mathrm{LB}}-18-007$ & $50 \mathrm{~g}$
\end{tabular}

RT = Right Thigh, RB = Right Breast, LT = Left Thigh, LB = Left Breast, L= liver, $\mathrm{K}=$ kidney, SP = Spiked Broiler chicken

Table 2: Microtiter plate layout for tetracycline analysis by ELISA

\begin{tabular}{|c|c|c|c|c|c|c|c|c|c|c|c|c|}
\hline & 1 & 2 & 3 & 4 & 5 & 6 & 7 & 8 & 9 & 10 & 11 & 12 \\
\hline $\mathrm{A}$ & B & B & CK-1 $1_{\mathrm{RT}}$ & CK-1 $1_{\mathrm{RT}}$ & CK- $1_{\mathrm{RB}}$ & CK- $1_{\mathrm{RB}}$ & CK-1 $1_{\text {LT }}$ & CK-1 $1_{\mathrm{LT}}$ & CK- $1_{\mathrm{LB}}$ & CK-1 $1_{\mathrm{LB}}$ & CK-1 $1_{\mathrm{L}}$ & CK-1 $1_{\mathrm{L}}$ \\
\hline B & $\mathrm{S}_{0}$ & $\mathrm{~S}_{0}$ & CK- $2_{\text {RT }}$ & $\mathrm{CK}-2_{\mathrm{RT}}$ & $\mathrm{CK}-2_{\mathrm{RB}}$ & $\mathrm{CK}-2_{\mathrm{RB}}$ & CK-2 2 LT & CK-2 2 & CK- $2_{\mathrm{LB}}$ & $\mathrm{CK}-2_{\mathrm{LB}}$ & CK-2 2 & CK- $2 \mathrm{~L}$ \\
\hline $\mathrm{F}$ & $S_{0.0625}$ & $\mathrm{~S}_{1}$ & CK- $3_{\mathrm{RT}}$ & $\mathrm{CK}-3_{\mathrm{RT}}$ & CK- $3_{\text {RB }}$ & CK- $3_{\text {RB }}$ & CK- $-3_{\text {LT }}$ & CK- $-3_{\text {LT }}$ & CK- $3_{\mathrm{LB}}$ & CK- $3_{\text {LB }}$ & $\mathrm{CK}-3_{\mathrm{L}}$ & CK- $3_{\mathrm{L}}$ \\
\hline D & $\mathrm{S}_{0.125}$ & $\mathrm{~S}_{2}$ & CK- $4_{\mathrm{RT}}$ & CK- $-4_{\mathrm{RT}}$ & $\mathrm{CK}-4_{\mathrm{RB}}$ & $\mathrm{CK}-4_{\mathrm{RB}}$ & CK- $4_{\text {LT }}$ & CK- $-4_{\text {LT }}$ & CK- $4_{\mathrm{LB}}$ & CK- $-4_{\text {LB }}$ & $\mathrm{CK}-4_{\mathrm{L}}$ & CK- $4_{\mathrm{L}}$ \\
\hline E & $\mathrm{S}_{0.25}$ & $\mathrm{~S}_{3}$ & CK- $5_{\mathrm{RT}}$ & $\mathrm{CK}-5_{\mathrm{RT}}$ & $\mathrm{CK}-5_{\mathrm{RB}}$ & CK- $5_{\mathrm{RB}}$ & CK- $5_{L T}$ & CK- $5_{\mathrm{LT}}$ & CK- $5_{\mathrm{LB}}$ & $C K-5_{L B}$ & $\mathrm{CK}-5_{\mathrm{L}}$ & CK- $5_{L}$ \\
\hline F & $\mathrm{S}_{0.5}$ & $\mathrm{~S}_{4}$ & CK- $6_{\mathrm{RT}}$ & CK-6 $6_{\text {RT }}$ & $\mathrm{CK}-6_{\mathrm{RB}}$ & $\mathrm{CK}-6_{\mathrm{RB}}$ & $\mathrm{CK}-1_{\mathrm{K}}$ & $\mathrm{CK}-1_{\mathrm{K}}$ & $\mathrm{CK}-4_{\mathrm{K}}$ & $\mathrm{CK}-4_{\mathrm{K}}$ & CK-6 $6_{L}$ & CK- $6_{\mathrm{L}}$ \\
\hline G & $S_{1.0}$ & $\mathrm{~S}_{5}$ & SP- $6_{\mathrm{RT}}$ & SP- $6_{\mathrm{RT}}$ & SP- $6_{\mathrm{RB}}$ & SP- $6_{\mathrm{RB}}$ & CK- $2_{\mathrm{K}}$ & CK- $2_{\mathrm{K}}$ & CK- $5_{\mathrm{K}}$ & CK- $5_{\mathrm{K}}$ & SP-6 ${ }_{L}$ & SP- $6_{\mathrm{L}}$ \\
\hline $\mathrm{H}$ & $\mathrm{S}_{2 \cdot 0}$ & $\mathrm{~S}_{2.0}$ & SP- $6_{\mathrm{LT}}$ & SP-6 ${ }_{L T}$ & SP-6 ${ }_{\mathrm{LB}}$ & SP-6 $6_{\mathrm{LB}}$ & CK- $3_{K}$ & CK- $3_{K}$ & CK- $6_{K}$ & CK-6 ${ }_{\mathrm{K}}$ & SP-6L & SP-6L \\
\hline
\end{tabular}

cellulose filter paper in the separatory funnel. To remove fat from supernatants, mixed with n-hexane (VWR), then transfer lower layer in Erlenmeyer flask (Pyrex) and kept for sample loading. SPE cartridge assembly (Phenomenex) was used for cleanup of samples using cartridges, lower layer was passed over C18 SPE Cartridges (Strata C18-E, (55 $\mu \mathrm{m}, 70 \mathrm{~A}$, Phenomenex, $500 \mathrm{mg} / 6 \mathrm{~mL})$. Cartridges were conditioned with $20 \mathrm{~mL}$ methanol and $20 \mathrm{~mL}$ double distilled water, the combined supernatant (treated sample) were loaded and desired analyte were eluted with $4 \mathrm{~mL}$ of $0.01 M$ Oxalic acid (Merck) in $\mathrm{MeOH}$ (VWR). The sample was dried using Evap. system having capacity 24 samples at a time (Romer labs, USA) at $35-40^{\circ} \mathrm{C}$ under vacuum. Re-constitute extract with $400 \mu \mathrm{L}$ mobile phase $0.1 \%$ TFA: ACN (75:25) v/v Vortex and filter with $0.45 \mu \mathrm{m}$ nylon membranes (PTFE membrane syringe filters, $4 \mathrm{~mm}, 0.45 \mu \mathrm{m}$ ) in sample injection vial (VWR) for injection to Amber glass vial $1.5 \mathrm{~mL}$ VWR HPLC grade for determination of oxytetracycline residues.

\section{Preparation of calibration curve}

Different oxytetracycline working standards (above and below the EU MRL) including 25, 50, 100 and $200 \mu \mathrm{g} \mathrm{kg}^{-1}$ were used for standardization and validation studies. Calibration curve was prepared between concentration and their respective areas to determine limit of detection (LOD) and limit of quantification (LOQ) for method.

\section{Results}

Temperature and weight of each animal was recorded twice a day throughout the experimental duration (one month). When animals gained average weight of $600 \pm 20 \mathrm{~g}$, then they were considered for the recommended dose as desired in experiment. Applied drug was also standardized with HPLC method with provided conditions and good response was observed. The declared period for Oxytetracycline in injectable (Hydrochloride salt, 20 ppk) dose was 5 days before slaughtering.

\section{Screening of samples through ELISA}

ELISA kit was standardized by calculating inhibition conc. $\mathrm{IC}_{20}$ and $\mathrm{IC}_{50}$ (criteria for test performance), relative absorbance found inversely proportional to the concentration of the tetracycline. A linear regression was obtained $(y=-20.86 \ln (x)+34.762)$ with correlation $\left(r^{2}\right)$ of 0.9996 as shown by Fig. 1. To check criteria for test performance, lowest detection limit $\left(\mathrm{IC}_{20}\right)$ and middle of the test $\left(\mathrm{IC}_{50}\right)$ were found to be $0.12 \mu \mathrm{g} \mathrm{kg}^{-1}$ and $0.5 \mu \mathrm{g} \mathrm{kg}^{-1}$, respectively which is well below the maximum residue limit for tissue (200 $\mu \mathrm{g} \mathrm{kg}^{-1}$ ). According to Fig. 2, average concentrations of oxytetracycline in poultry tissues decreased gradually with time and after $117 \mathrm{~h}$, residues were found well below the MRL value. The detectable residue concentrations were calculated as 4870, 4062, 3354, 3142, 1556 and $101 \mu \mathrm{g} \mathrm{kg}^{-1}$ at 1, 8, 16, 32, 64 and $120 \mathrm{~h}$ intervals, respectively. Results showed that declared period in proportion to our findings. These are not in accordance to Bangladesh due to may be difference in environmental conditions (Khatun et al. 2018).

In order to check the drug distribution profile, it was found that concentration of the left sides (breast/thigh) was lowered than right side of broiler chicken as shown by Table 3. Most important is that the treated samples were compared with non-treated and concentration was negligible and declared as negative control. It was cleared that the residues found in kidney and liver was more than other parts of body, this is because organs of metabolism and excretion were expected to have higher concentrations of these residues than breast and thigh tissue. In order to calculate recovery (\%), known negative samples (tissue, kidney and liver) were spiked with different oxytetracycline concentrations below 
Depletion Profile of Oxytetracycline in Poultry Meat / Intl J Agric Biol, Vol 26, No 6, 2021

Table 3: Oxytetracycline residue depletion in treated poultry by ELISA $(n=3)$

\begin{tabular}{|c|c|c|c|c|c|c|c|}
\hline \multirow[t]{2}{*}{ Withdrawal time (h) } & \multirow[t]{2}{*}{ Animal No. } & \multicolumn{6}{|c|}{ Concentration $\left(\mu \mathrm{g} \mathrm{kg}^{-1}\right)$ in different chicken tissues } \\
\hline & & $\overline{\mathrm{RB}}$ & LB & RT & LT & Kidney & Liver \\
\hline 1 & 1 & 2120 & 1680 & 2304 & 24 & 2020 & 2480 \\
\hline 8 & 2 & 22000 & 2256 & 2200 & 2340 & 2600 & 2400 \\
\hline 32 & 4 & 1500 & 1640 & 1632 & 1540 & 2160 & 1440 \\
\hline 64 & 5 & 288 & 298 & 500 & 750 & 560 & 1481 \\
\hline 120 & 6 & 150 & 97 & 101 & 144 & 540 & 580 \\
\hline
\end{tabular}

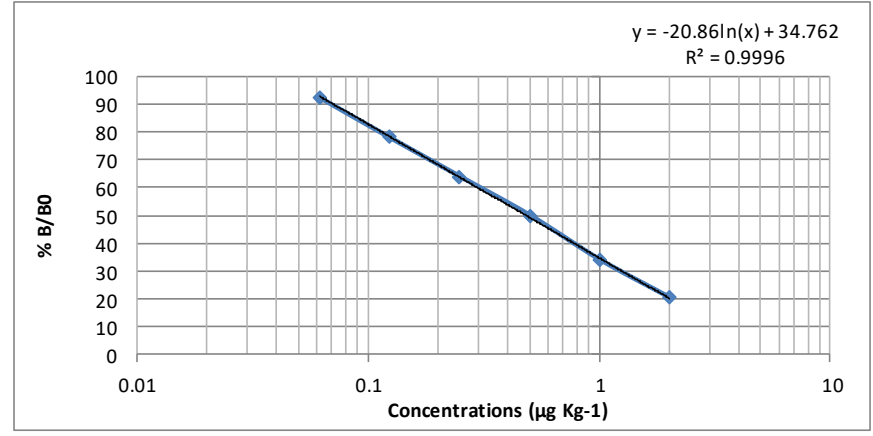

Fig. 1: Standard curve used for Oxytetracycline detection in chicken tissue by ELISA

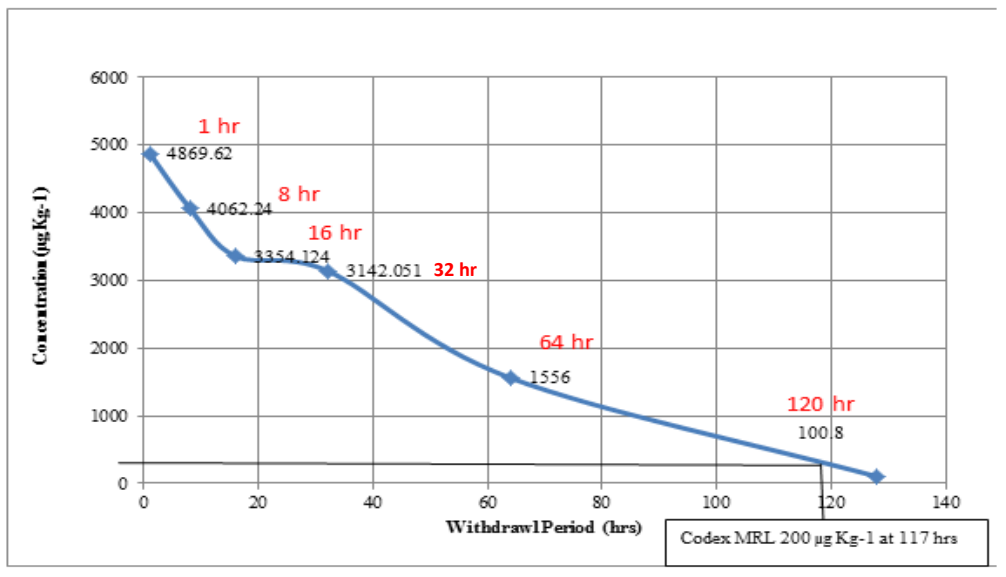

Fig. 2: Withdrawal period of Oxytetracycline in broiler chicken through ELISA

and above the MRL. Overall results indicated that recovery was calculated from 75 to $86 \%$ as shown in Table 4.

\section{Standardization and validation by HPLC-UV}

Before confirmatory analysis, standardization was done on at four different days by using HPLC UV-Vis detector. Good linearity of calibration curve was found through regression equation $\mathrm{y}=\mathrm{mx}+\mathrm{C}$ with ccorrelation coefficient $\left(\mathrm{R}^{2}\right) 0.9724$ using different oxytetracycline working standards including 25, 50, 100 and $200 \mu \mathrm{g} \mathrm{kg}^{-}$ ${ }^{1}$ (Fig. 3). Retention time was found as $1.85 \pm 0.03 \mathrm{~min}$ and peaks area was found directly proportional to the standard concentration 25, 50, 100 and $200 \mu \mathrm{g} \mathrm{kg}^{-1}$ (Fig. 4). After $128 \mathrm{~h}$, oxytetracycline residues were found less than MRL i.e., $200 \mu \mathrm{g} \mathrm{kg}-1$ as shown by Fig. 5 and reported values are in Table 5.

\section{Discussion}

This study relates to the public safety and awareness to the local farmers for safe handling of drugs. Oxytetracycline is being used as drug to enhance the growth of the poultry (Bosha et al. 2019). In order to meet the validation criteria, all parameters were followed as per 657/2002/EC guidelines (GL49 2015). The usage of the commercial drug in the animal then their residues still retained the body even till $120 \mathrm{~h}$. The HPLC validated method employed for analysis is accurate and capable of determining the tetracyclines precisely over the concentration range 25 to $250 \mathrm{ppb}$.

The LOD value is minimum amount of the analyte detected, calculated as $\mathrm{Xn}+3 \mathrm{SD}$ under optimal conditions. 
Mumtaz et al. / Intl J Agric Biol, Vol 26, No 6, 2021

Table 4: Recovery calculations of different Oxytetracycline concentrations in known negative samples $(\mathrm{n}=3)$

\begin{tabular}{llllll}
\hline Matrix & Spiking Conc. $\left(\mu \mathrm{g} \mathrm{kg}^{-1}\right)$ & \multicolumn{2}{c}{ Analysis by ELISA } & \multicolumn{2}{c}{ Analysis by HPLC } \\
\cline { 3 - 6 } & & Recovery $(\%)$ & Recovery $(\%)$ & CV \\
\hline Liver & 100 & 75 & 5.4 & 85 & 3.8 \\
& 150 & 82 & 3.8 & 87 & 2.8 \\
Kidney & 200 & 85 & 4.5 & 92 & 3.8 \\
& 100 & 79 & 3.5 & 87 & 2.8 \\
\multirow{4}{*}{ Muscle } & 150 & 85 & 5.4 & 86 & 6.7 \\
& 100 & 82 & 6.5 & 93 & 8.6 \\
& 150 & 82 & 3.2 & 86 & 3.8 \\
& 200 & 86 & 2.4 & 92 & 3.9 \\
\hline
\end{tabular}

CV: Coefficient of variation

Table 5: Oxytetracycline residues depletion in treated poultry by HPLC $(n=3)$

\begin{tabular}{|c|c|c|c|c|c|c|c|}
\hline \multirow[t]{2}{*}{ Withdrawal time (h) } & \multirow[t]{2}{*}{ Animal No. } & \multicolumn{6}{|c|}{ Concentration $\left(\mu \mathrm{g} \mathrm{kg}^{-1}\right)$ in different chicken tissues } \\
\hline & & $\mathrm{RB}$ & LB & RT & LT & Kidney & Liver \\
\hline$\overline{1}$ & 1 & 7164 & 5844 & 7195 & 5150 & 1076 & 2786 \\
\hline 8 & 2 & 5139 & 6095 & 4736 & 4820 & 763 & 2819 \\
\hline 32 & 4 & 1425 & 4421 & 4702 & 4341 & 995 & 1800 \\
\hline 64 & 5 & 680 & 179 & 2800 & 280 & 890 & 1785 \\
\hline 120 & 6 & 210 & 21 & 235 & 80 & 838 & 1741 \\
\hline
\end{tabular}

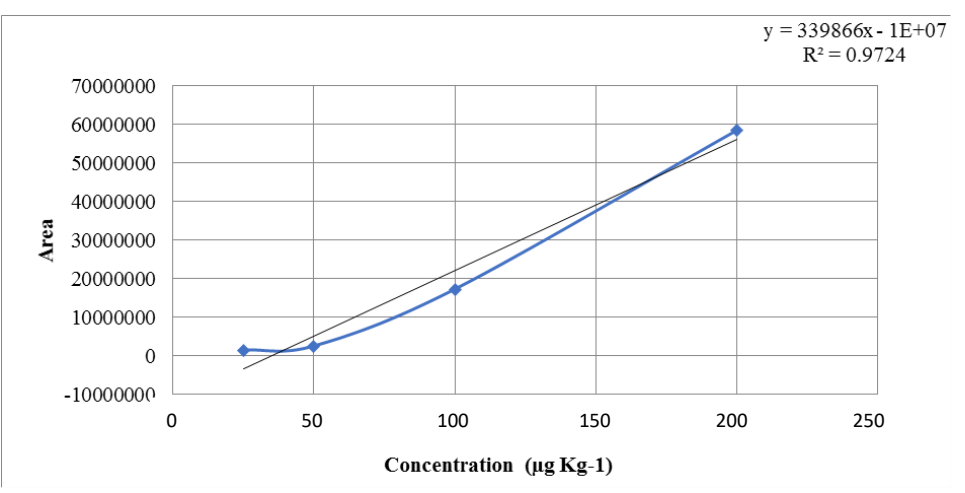

Fig. 3: Standard curve used for Oxytetracycline detection in chicken tissue by HPLC

Similarly, the LOQ is smallest quantity of analyte that can be measured with acceptable accuracy and precision (95\% confidence level). The LOQ was found by calculating recovery and precision data i.e., $\mathrm{CV}$, and was defined as the lowest validated spike level meeting the requirements of a recovery was found from 85 to $93 \%$ by spiked samples with oxytetracycline by HPLC as shown by Table 6. LOD and LOQ of the method were found to be 16 and $25 \mu \mathrm{g} \mathrm{kg}^{-1}$ respectively. Signal to noise ratio was found to be $3: 1$ in acceptable range.

Most important findings are that the concentrations of the tetracycline were varied between slaughtered samplings. The possible reason is the reabsorption or recirculation of OTC in the birds' body to other organs or parts. As a target tissue bone tissue (breast/chest) were collected along with lever and kidney, detected OTC concentrations in treated broiler chicken bone tissue. It is also being reported that this were a more complex link takes place between the tissue and the rings of the basic tetracycline structure (GL49 2015; Odore et al. 2015). Most important is that the treated samples were compared with non-treated and concentration was negligible and declared as negative control (Khatun et al. 2018). It was cleared that the residues found in kidney and liver was more than other parts of body, this is because organs of metabolism and excretion were expected to have higher concentrations of these residues than breast and thigh tissue.

Further, it is very important to consider the interaction of the drug with the body, OTC is lipophilic with a large distribution volume, because of this reason the concentration in edible tissue was found higher (Mestorino et al. 2007). Further, it can be evaluated that by passage of time concentration in the body parts decreases but definitely it is continuously deposited in the manure/droppings. Literature provides evidence that droppings may be a route of contamination and dissemination of OTC residues in the environment indeed a great health risk for the soil microflora. Poultry birds were free to move in specified place and as a result dust in the air can result in the dissemination of OTC from treated to untreated birds. The long half-life of OTC and 
Depletion Profile of Oxytetracycline in Poultry Meat / Intl J Agric Biol, Vol 26, No 6, 2021

Table 6: Recoveries of Oxytetracycline spiked matrices collected from control poultry $(n=3)$

\begin{tabular}{|c|c|c|c|c|c|}
\hline \multirow{2}{*}{ Matrix } & \multirow[t]{2}{*}{ Spiking Concentration $\left(\mu \mathrm{g} \mathrm{kg}^{-1}\right)$} & \multicolumn{2}{|c|}{ Analysis by ELISA } & \multicolumn{2}{|c|}{ Analysis by HPLC } \\
\hline & & Recovery (\%) & $\mathrm{CV}^{\mathrm{a}}(\%)$ & Recovery $(\%)$ & $\mathrm{CV}^{\mathrm{a}}(\%)$ \\
\hline \multirow[t]{3}{*}{ Liver } & 100 & 75 & 5.4 & 85 & 3.8 \\
\hline & 150 & 82 & 3.8 & 87 & 2.8 \\
\hline & 200 & 85 & 4.5 & 92 & 3.8 \\
\hline \multirow[t]{3}{*}{ Kidney } & 100 & 79 & 3.5 & 87 & 2.8 \\
\hline & 150 & 85 & 5.4 & 86 & 6.7 \\
\hline & 200 & 82 & 6.5 & 93 & 8.6 \\
\hline \multirow[t]{3}{*}{ Muscle } & 100 & 82 & 3.2 & 86 & 3.8 \\
\hline & 150 & 86 & 2.4 & 92 & 3.9 \\
\hline & 200 & 75 & 1.5 & 85 & 5.4 \\
\hline
\end{tabular}

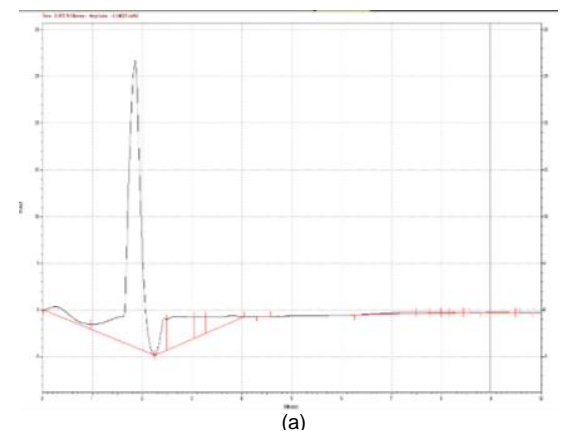

(a)

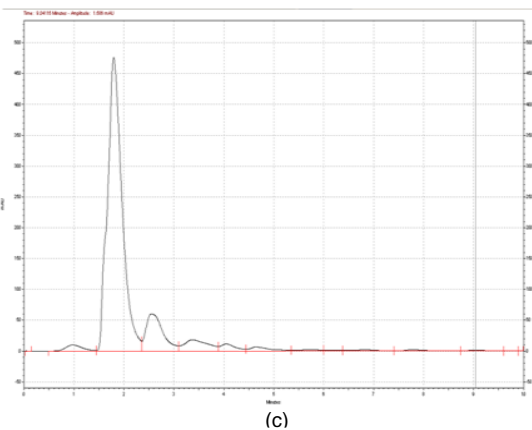

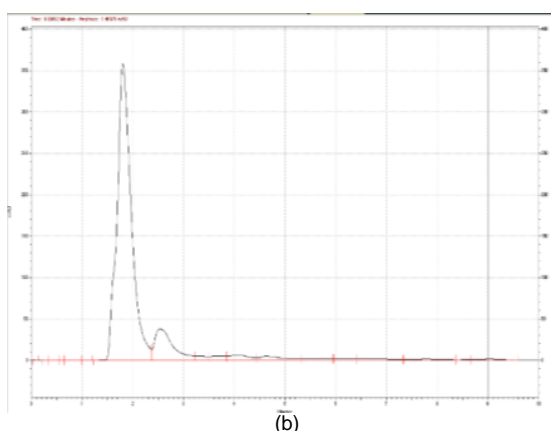

(b)

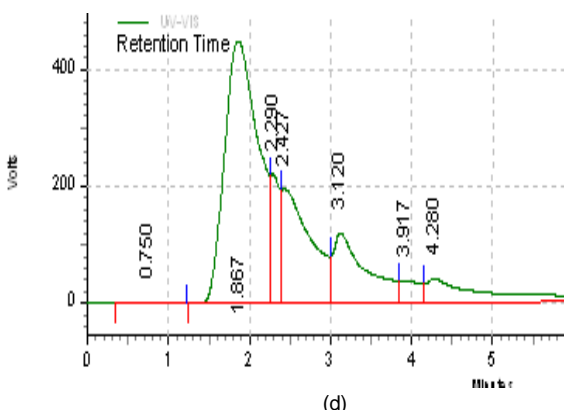

(d)

Fig. 4: Oxytetracycline chromatographs of standards and sample (a) $50 \mu \mathrm{g} \mathrm{kg}^{-1}$ (b) $100 \mu \mathrm{g} \mathrm{kg}^{-1}$ (c) $200 \mu \mathrm{g} \mathrm{kg}{ }^{-1}$ and (d) Oxytetracycline treated tissue

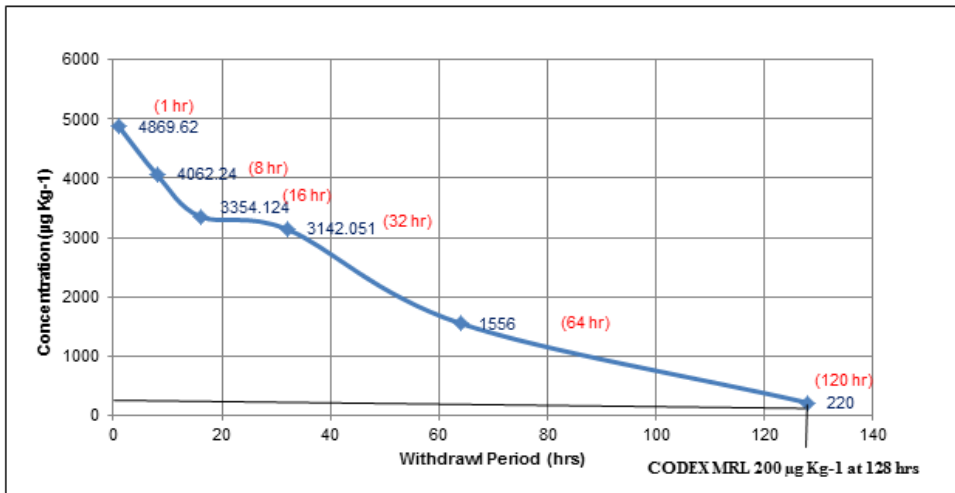

Fig. 5: Withdrawal period of Oxytetracycline in broiler chicken through HPLC

the use of broiler droppings to fertilize soil also present a risk for the transfer and persistence of OTC. It is a threat to the food cycle that excretion of Oxytetracycline bind to soil
(Carballo et al. 2016; Pokrant et al. 2021).

Withdrawal period reported by Bangladesh research article is not resembled to our findings, it is due to difference 
in environmental conditions. In comparison to Bangladesh, the withdrawal periods for oxytetracycline in poultry birds were found greater throughout the study period on all visited farms. That's why; they set the different MRP value to control illegal use of oxytetracycline. This means residue value of oxytetracycline can be used in marketed poultry which was found in the build-up relationship study as shown by the research article (Khatun et al. 2018). Regression equation was found to be $\mathrm{y}=339866 \mathrm{x}=\mathrm{E}^{+07}$ for confirmatory analysis, $R^{2}=0.9724$ as shown in Fig. 3 and chromatograms Fig. 4. Our findings are in accordance with other studies (Cinquina et al. 2003).

So, in our experiment maximum oxytetracycline residue values in marketed poultry were found after one hour followed by drug administration. The present finding is agreed by researchers (Agha et al. 2003). According to FARAD digest, withdrawal period in egg laying poultry for tetracycline were approximately more than 5 days in Ireland, Canada, US and Australia (Marmulak et al. 2015). Our results are in accordance with Mund et al. (2017) as withdrawal period was observed 5 days. However, only trace concentrations of OTC were detected in droppings and litter from sentinel birds. These findings establish the first evidence that there is a low likelihood of the transfer of OTC residues from treated birds to the environment and to untreated birds in adjacent or separate pens, which needs to be further studied.

\section{Conclusion}

This study provides the depletion and distribution of oxytetracycline in edible parts of broiler chicken like muscles, liver and kidney. Withdrawal period of oxytetracycline was calculated $117 \mathrm{~h}$ by ELISA while $128 \mathrm{~h}$ by HPLC. It is of great concern especially for the farmers to wait until the residues of the injected dose becomes less than the MRL. According to the study, it is strongly suggested that the need for more stringer regulatory authorities for the use of antibiotics in the poultry farms, as well as the survey of chicken for drug residues prior to marketing.

\section{Acknowledgments}

We are grateful to the International Atomic Energy Commission (IAEA) for providing commercial ELISA kits under Technical Cooperation Project RAS 5078 entitled "Enhancing food safety laboratory capabilities and establishing a network in Asia to control veterinary drug residues and related chemical components" to develop validated protocols for monitoring veterinary drug residues in different food matrices.

\section{Author Contributions}

MM planned experiments and conducted sampling, analysis, interpretation of results, and write up. UM contributed in planning of experiment. MIC and MSS contributed in the experiment execution and write up. $\mathrm{GH}$ helped during collection of samples and analysis.

\section{Conflicts of Interest}

All authors declare no conflict of interest.

\section{Data Availability}

Data presented in this study will be available on a fair request to the corresponding author.

\section{Ethics Approval}

Experiment was conducted at Animal House, NIAB with proper handling and as per ARRIVE guidelines.

\section{References}

Agha DS, R Goldfish, P Kulshrestha (2003). Application of ELISA in determining the fate of tetracyclines in land-applied livestock wastes. Analyst 128:658-662

Al-Gendy HM, FS Hasanen, AM Salem, SM Nada (2014). Assessment of oxytetracycline and ampicillin residues in sheep carcasses. Benha Vet Med J 27:188-196

Ang JJD, SLS Estaniel, LP Guidote (2017). Extraction and Determination of Tetracyclines in Chicken Meat by Solid Phase Extraction and High Performance Liquid Chromatography, DLSU Research Congress Food, Nutrition \& Health Proceeding FNH-II-013, Manila, Philippines

Biswas AK, GS Rao, N Kondaiah, ASR Anjaneyulu, SK Mendiratta, R Prasad, JK Malik (2007). A simple multi-residue method for determination of oxytetracycline, tetracycline and chlortetracycline in export buffalo meat by HPLC-photodiode array detector. J Food Drug Anal 15:1-7

Bosha JO, AF Gberindyer, PA Onyeyili (2019). Pharmacoepidemiology of tetracycline usage by poultry practitioners in Makurdi Metropolis. Drugs 14:96-107

Carballo M, S Aguayo, M González, F Esperon, ADL Torre (2016). Environmental assessment of tetracycline's residues detected in pig slurry and poultry manure. J Environ Prot 7:82-92

Cinquina AL, F Longo, G Anastasi, L Giannetti, R Cozzani (2003). Validation of a high-performance liquid chromatography method for the determination of oxytetracycline, tetracycline, chlortetracycline and doxycycline in bovine milk and muscle. J Chromatogr A 987:227-233

CODEX (2012). Maximum Residue Limits for Veterinary Drugs in Foods, pp: $1-40$. Updated as at the $35^{\text {th }}$ Session of the Codex Alimentarius Commission. CAC/MRL

CODEX (2018). Maximum Residue Limits (MRLs) and Risk Management Recommendations (RMRs) for Residues of Vterinary Drugs in Foods. CX/MRL 2-2018

Comission Decision 2002/657/EC (2002). Commission Decision of 12 August 2002 implementing Council Directive 96/23/EC concerning the performance of analytical methods and the interpretation of results. Official J EU Communities, Luxembourg

EURegulation (2010). No. 37/2010 of 22 December 2009 on pharmacologically active substances and their classification regarding maximum residue limits in foodstuffs of animal origin. Off $J E U$ 15:1-72

Khatun R, AJ Howlader, S Ahmed, N Islam, K Alam, S Haider, MS Mahmud, MA Hasan (2018). Validation of the declared withdrawal periods of antibiotics. Univ J Public Health 6:14-22

Marmulak T, LA Tell, R Gehring, RE Baynes, TW Vickroy, JE Riviere (2015). Egg residue considerations during the treatment of backyard poultry. J Amer Vet Med 247:1388-1395 


\section{Depletion Profile of Oxytetracycline in Poultry Meat / Intl J Agric Biol, Vol 26, No 6, 2021}

Mestorino N, EM Hernández, L Marchetti, JO Errecalde (2007). Pharmacokinetics and tissue residues of an oxytetracycline/diclofenac combination in cattle. Rev Sci Technol 26:679-690

Muaz K, M Riaz, S Akhtar, S Park, A Ismail (2018). Antibiotic residues in chicken meat: global prevalence, threats, and decontamination strategies: a review. J Food Prot 81:619-627

Mund MD, UH Khan, U Tahir, BE Mustafa, A Fayyaz (2017). Antimicrobial drug residues in poultry products and implications on public health: A review. Intl J Food Prop 20:1433-1446

Odore R, MD Marco, L Gasco, L Rotolo, V Meucci, A Palatucci, V Rubino, G Ruggiero, S Canello, G Guidetti (2015). Cytotoxic effects of oxytetracycline residues in the bones of broiler chickens following therapeutic oral administration of a water formulation. Poult Sci 94: 1979-1985

Pokrant E, K Yévenes, L Trincado, G Terraza, N Galarce, A Maddaleno, BS Martín, L Lapierre, J Cornejo (2021). Evaluation of antibiotic dissemination into the environment and untreated animals, by analysis of oxytetracycline in poultry droppings and litter.Animals 11; Article 853
Rana MS, SY Lee, HJ Kang, SJ Hur (2019). Reducing veterinary drug residues in animal products: A review. Food Sci Anim Res 39:687703

Riviere JE, MG Papich (2018). Veterinary Pharmacology and Therapeutics, John Wiley \& Sons, New York, USA

Shahid MA, M Siddique, M Abubakar, M Arshed, M Asif, A Ahmad (2007). Status of oxytetracycline residues in chicken meat in Rawalpindi/Islamabad area of Pakistan. Asian J Poult Sci 1:8-15

Wang J, JD MacNeil, JF Kay (2011). Chemical Analysis of Antibiotic Residues in Food. John Wiley \& Sons, New York, USA

Widiastuti R, Y Anastasia (2015). Detection of oxytetracycline in broiler chicken meat marketed in several cities in java island using enzymelinked immunosorbent assay (ELISA) method. J Indo Trop Anim Agric 40:52-58

Xu N, M Li, Y Fu, X Zhang, X Ai, Z Lin (2019). Tissue residue depletion kinetics and withdrawal time estimation of doxycycline in grass carp, Ctenopharyngodon idella, following multiple oral administrations. Food Chem Toxicol 131; Article 110592 